\title{
BMJ Open Stakeholder attitudes towards the role and application of informed consent for newborn bloodspot screening: a study protocol
}

\author{
S G Nicholls, ${ }^{1}$ L Tessier, ${ }^{1}$ H Etchegary, ${ }^{2} \mathrm{~J}$ C Brehaut, ${ }^{3,1}$ B K Potter, ${ }^{1}$ \\ R Z Hayeems, ${ }^{4,5}$ P Chakraborty, ${ }^{6} \mathrm{~J} \mathrm{Marcadier}^{6}{ }^{6} \mathrm{~J} \mathrm{Milburn},{ }^{7} \mathrm{D}$ Pullman, ${ }^{8}$ \\ L Turner, ${ }^{9} \mathrm{~B} \mathrm{~J}$ Wilson ${ }^{1}$
}

To cite: Nicholls SG,

Tessier L, Etchegary $\mathrm{H}$, et al. Stakeholder attitudes towards the role and application of informed consent for newborn bloodspot screening: a study protocol. BMJ Open 2014;4:e006782. doi:10.1136/bmjopen-2014006782

- Prepublication history for this paper is available online To view these files please visit the journal online (http://dx.doi.org/10.1136/ bmjopen-2014-006782)

Received 29 September 2014 Accepted 22 October 2014

CrossMark

For numbered affiliations see end of article.

Correspondence to Dr S G Nicholls; snicholl@uottawa.ca

\section{ABSTRACT}

Introduction: Newborn bloodspot screening (NBS) involves testing a small sample of blood taken from the heel of the newborn for a number of serious and lifelimiting conditions. In Canada, newborn screening programmes fall under provincial and territorial jurisdiction with no federal coordination. To date, we know very little about the underlying beliefs around different consent practices or how terminology is interpreted by different individuals. Differences in attitudes may have important healthcare consequences. This study will provide empirical data comparing stakeholder opinions on their understanding of consent-related terminology, the perceived applicability of different consent approaches to newborn screening, and the requirements of these different approaches.

Methods and analysis: Parents, healthcare professionals and policymakers will be recruited in the provinces of Ontario and Newfoundland and Labrador. Parents will be identified through records held by each provincial screening programme. Healthcare professionals will be purposively sampled on the basis of engagement with newborn screening. Within each province we will identify policymakers who have policy analysis or advisory responsibilities relating to NBS. Data collection will be by qualitative interviews. We will conduct 20 interviews with parents of young children, 10 interviews with key healthcare professionals across the range of appropriate specialties and 10 with policymakers at each site ( 40 per site, total, $\mathrm{N}=80$ ). The examination of the transcripts will follow a thematic analysis approach. Recruitment started in June 2014 and is expected to be complete by June 2015.

Ethics and dissemination: This study received ethics approval from the Ottawa Health Science Network Research Ethics Board, the Children's Hospital of Eastern Ontario Research Ethics Board (both Ontario), and the Health Research Ethics Authority (Newfoundland and Labrador).

Results: These will be reported in peer-reviewed publications and conference presentations. The results will have specific application to the development of parent education materials for newborn screening.

\section{INTRODUCTION}

Newborn bloodspot screening (NBS) is one of the oldest and most wide-spread population-based screening programmes in the world, with programmes existing in most continents. ${ }^{1-6}$ NBS involves testing a small sample of blood taken from the heel of the newborn for a number of serious and lifelimiting conditions. Having recently celebrated 50 years since first being introduced in the USA, NBS has been recognised by the Centers for Disease Control as 1 of 10 great public health achievements of the last decade. Despite this longevity and international presence, the implementation of NBS varies across Canada, and internationally, in terms of the number of conditions included in the screening panels, ${ }^{78}$ but also the educational materials provided to parents $^{9}$ and approaches to consent. ${ }^{7}$

NBS illustrates the effect of the 'technological imperative'-dramatic developments in technological capabilities have made it easy to expand the number of conditions screened for at marginal extra cost. ${ }^{510-17}$ The expansion of screening in some jurisdictions to include conditions where natural history and clinical intervention have been less well characterised, together with an increased emphasis on information provision as a benefit of newborn screening, has prompted renewed discussion about consent processes for NBS. ${ }^{18-26}$ In part this relates to a shift in the balance between benefits and potential harms, particularly those associated with false positive results, such as parental distress or impaired parent child bonding. ${ }^{27-30}$ At one end of the spectrum are programmes where non-participation is essentially not an option: for example, several newborn screening programmes in the US are mandated. ${ }^{31} 32$ At the 
other end of the spectrum lie jurisdictions, such as the UK, in which screening is offered explicitly on a choice basis. ${ }^{33}$ In Canada, an opt-out approach has generally been taken whereby screening occurs by default unless there is a specific objection by the parents. ${ }^{34-36}$

There is now an abundance of qualitative data on parental attitudes toward the provision of NBS. ${ }^{20} 223337-41$ While this research shows support for screening, there are varied, and occasionally conflicting, attitudes toward consent approaches. In a Canadian study, Haveems et $a t^{42}$ found that while $79 \%$ of parents indicated that screening should be required for highly treatable conditions, $54 \%$ also indicated that parents should be "able to choose without pressure whether to have their baby screened". As such, a substantial proportion supported both mandated interventions and parental authorisation. Studies have also found significant variation in healthcare professionals' attitudes to consent in NBS. ${ }^{36} 43$

However, an assumption within existing research is that terminology, such as 'informed consent', is understood equally by all stakeholders, in all contexts. Recent studies indicate this may not be the case. The attitudes of healthcare professionals toward different consent approaches in the study by Miller $e t a l,{ }^{36}$ appear to be highly dependent on how practitioners conceived of consent and the requirements that this would impose. They note, for example, that some healthcare professionals felt that informed consent for newborn screening was not practical. They report comments from a paediatrician whose attitude toward the application of informed consent appears highly contingent on the practicalities and perceived burdens of obtaining consent, stating that "Consent is not practical because you'd have to go into a discussion about every single disease that you can test for and every single result you potentially can get. If you, if it's truly to be informed consent". However, other healthcare professionals' comments suggested a different interpretation of the requirements consent approaches impose, again appearing to inform their attitudes toward consent for newborn screening. As one midwife replied others indicated a less complex view of the requirements to obtain informed consent and that "[it's] not rocket science ... and it's not time-consuming to do and people get it". ${ }^{36}$

Furthermore, research has neglected a third stakeholder group: those involved in policy development. Indeed, given the jurisdictional variations in NBS consent practices, it is important to explore the rationale behind screening policy decisions to identify areas of commonality and difference. The exclusion of those involved in policy development may reflect a view that they are too far removed from the clinical encounter. ${ }^{44}$ However, if policy decisions are incongruent with clinical customs then parents may suffer through inconsistent practice. One study points to the importance of effective communication between providers and parents in this respect. ${ }^{45}$

To date, there has been no exploration of different interpretations of the concept of informed consent, nor how this affects attitudes, practice, and experience toward consent approaches for NBS. There is a lack of comparative research that includes the three key stakeholder groups in NBS, and a paucity of studies comparing attitudes and experiences across jurisdictions. This study will address these deficits by explicitly examining understandings of consent processes within two divergent NBS programmes in Canada, involving the three stakeholder groups. The results will highlight areas important for parent and professional education and policy development, as well as further our understanding of the interpretation of consent approaches. Specifically, we will:

1. Examine how current consent practices to NBS are described and experienced by different stakeholders;

2. Explore individual meanings of terms such as 'informed consent', 'standard of care', and 'implied consent';

3. Describe attitudes toward different approaches to NBS that exist along the spectrum from mandated to voluntary opt-in approaches.

This study will present the first empirical data comparing stakeholder opinions and experiences of consent practices to newborn screening. The findings will not only further our understanding of attitudes towards consent and how these affect experiences, but will also have specific application to the development of parent education materials for newborn screening insofar as discussion of experiences may point to identifiable informational messages that are working, and indicate other areas for development. Equally, discussion with healthcare professionals may identify areas of professional development in relation to consent practices.

\section{METHODS AND ANALYSIS}

\section{Study design}

This study will be qualitative in nature using semistructured interviews with key stakeholders-parents, healthcare professionals and policymakers. This will allow us to explore with stakeholders, in detail, key questions regarding perceptions of consent processes, attitudes towards these, and how these perceptions and attitudes relate to individual experiences.

\section{Research sites/settings}

The study will be conducted in parallel at two research sites: Ontario $(\mathrm{ON})$ and Newfoundland and Labrador (NL). These provinces differ in their screening programme composition and organisation. Ontario has the largest screening programme in Canada, and Newborn Screening Ontario (NSO) currently screens for 28 disorders. NSO screens over 140000 samples per year, with approximately 1300 screen positive referrals, of which around 150 are confirmed at diagnosis. Newfoundland and Labrador screens for only six conditions. With roughly 4500 births per year, this generates 
approximately 40-50 screen positive referrals, with approximately two true positives annually. Integrating findings from multiple stakeholders at two sites, we are able to strengthen the impact of results through the triangulation we achieve with multiple perspectives.

\section{Identification and recruitment of participants Parents}

Parents will be eligible for inclusion if they are over 18 years of age, their child has undergone newborn screening within either ON or NL during the past year, they currently reside in ON or NL, and can converse fluently in English or French. We will exclude parents where information is available, if the child is severely ill, has died or is under the care of Children's Aid or has been adopted. In addition, due to a lack of clinical outcome information in screen negative children, where records allow, we will exclude parents if their child was born at $<35$ weeks gestation or was transfusion positive. Both of these are indicators of poor health outcomes and invitation to interview may be distressing for the parents.

Parents will be identified through a purposive sampling approach. ${ }^{37}{ }^{46}$ We will identify parents on the basis of screening result (normal, false positive, true positive, or declined). For example, while the literature suggests that a number of parents may not see screening as a choice, those parents who actively decline screening may be qualitatively different to those accepting screening. Furthermore, given study findings that false positive results may have harms for parents, and that these may be mitigated to an extent by effective communication by professionals-as may be expected within a consent process-then the experiences of parents whose children have positive screening results should be sought and necessarily compared to true positives and true negatives in order to differentiate issues specifically relevant to the false positive result.

As such, we are deliberately identifying parents based on presumed differences in attitude or expectations generated by the screening result. The process of purposively identifying potential participants may, therefore, also be considered a process of maximum variation sampling due to the deliberate seeking of parents who may have opposing or contrasting experiences and perspectives. $^{47}$

All parents will be identified through records held by each provincial screening programme. Following review by a genetic counsellor or geneticist to ensure eligibility, parents will be approached in writing by a member of the clinical team. Potential participants will be sent an invitation letter, information sheet, consent form and return slip. In NL, parents of screen-negative newborns will receive a follow-up phone call approximately 2 weeks after receipt of the mailed study information. Owing to very small numbers in the NL site, parents whose newborns receive a true positive or false positive result, as well as those parents who decline NBS, will receive a phone call from the geneticist who provided care during the screening process prior to the mailed study information. The purpose of that call is to explain the study, answer any questions, mitigate any parental concerns and maximise recruitment of small numbers. All participants will also receive a small financial incentive to participate.

For parents who have chosen to decline newborn screening at the $\mathrm{ON}$ site, the healthcare professional responsible for the identified child will be contacted. The healthcare professional will receive a cover letter indicating the names of individuals under their care who have declined newborn screening. The healthcare professional will also receive a recruitment package for each individual identified (an invitation letter, information sheet and return slip) and will be asked to forward this to the identified individuals.

\section{Healthcare professionals}

Healthcare professionals will be purposively sampled based on their role in newborn screening and are eligible for inclusion if they are involved as submitters of blood spot samples to the provincial screening programme, or are actively involved in the provision of education regarding NBS. Eligible healthcare professionals include: obstetricians, paediatricians, nurses (maternal/newborn), midwives, family physicians and genetics professionals. ${ }^{36} 3839$ Healthcare professionals will be identified through information provided in screening reports, as well as existing professional and organisational networks representing these specialties. As with parents, all healthcare professionals will be contacted by a member of the clinical team who has appropriate access and contact information. Each participant will receive a recruitment package containing an invitation letter, information sheet, consent form and return slip.

\section{Policy decision-makers}

Within each province we will identify and recruit individuals who have policy analysis or advisory responsibilities relating to newborn bloodspot screening. In ON, Newborn Screening Ontario is governed and supported by a number of committees created by the Ministry of Health and Long Term Care to counsel them about appropriate policies regarding newborn and childhood screening. In NL, there is no formal policy decisionmaking process in place, with decisions made on an ad hoc basis. Individuals involved in recent decisions regarding newborn screening in NL will be identified by members of the research team. In addition, due to the anticipated lack of prior sampling frame, further recruitment of key informants will use a snowball sampling approach $^{40}{ }^{41}$ with interviewees identifying further interview participants.

In both ON and NL, policy decision-makers will be eligible for inclusion if they are past or present members of committees (standing or ad hoc) whose remit includes governance of, or policy advice relating to, newborn 
screening. Policy decision-makers will be excluded if their role relates only to receipt of advice, or they hold a generic position not specific to newborn screening. All potential participants will be approached in writing by the principal investigator.

All potential participants will receive by mail an invitation to take part in the study, along with a response slip, a stamped return envelope, and a copy of the information sheet and consent form. If individuals identified as eligible wish to take part, they will indicate this on a reply slip which will be returned in the provided envelope. Within this reply slip they will also be asked to provide contact details to be used to arrange an in-person or telephone interview. Should they wish to take part, they will be contacted using the provided information. Alternatively, on receipt of the study information, participants can contact the research team directly to indicate interest and arrange an interview time. On the agreed date, the participant will again confirm their intention to take part in the interview and consent to conduct the interview will be obtained. Figure 1 provides an overview of the recruitment process.

\section{Sample size}

Following established qualitative research methods, sample size is estimated at what will achieve saturation (ie, when new interviews cease to provide fresh information). ${ }^{37}$ 48-51 Approximate, sample sizes are based on the experience of the team. ${ }^{52-54}$ We will conduct 20 interviews with parents of young children, 10 interviews with key healthcare professionals across the range of appropriate specialties and 10 with policymakers at each site (40 per site, total, $\mathrm{N}=80$ ). However, as saturation of topics is the stated end point, additional interviews may be required. In line with Francis et $a l^{55}$ if we fail to achieve saturation within our initial sample size we will conduct additional interviews until we have conducted two interviews beyond during which no new themes or ideas emerge. ${ }^{55}$

\section{Data collection and management}

Semistructured interviews were chosen as they allow the respondents-here parents, healthcare professionals and policy decision-makers-to create their own definitions of experiences and attitudes, rather than having these imposed by the researcher. ${ }^{56}{ }^{57}$ In particular, given the noted variation in use of key terminology and conflicting attitudes toward consent reported within the literature, it is important to allow participants to define their use of terminology and its application to the context of newborn screening. Furthermore, the lack of confidentiality in focus groups may inhibit some parents (particularly those with children who were screen positive) from taking part. From a pragmatic perspective, the difficulty of convening a group discussion for professionals and policy decision-makers would have made the focus group methodology impractical.
Interviews with stakeholders will comprise two sections; (1) experiences of NBS and, (2) attitudes toward consent for NBS. Section 1, relating to experiences of NBS, will consist of questions that broadly map to previously defined components of informed choice, informed decision-making, and informed consent, such as experiences relating to the disclosure of information, deliberation, voluntariness of decision and competency ${ }^{58-60}$ For parents, a particular focus will be around experiences of the provision of information about newborn screening, perceptions regarding ability to decline, and their views regarding the decision-making process. Similarly, healthcare professionals and policy decisionmakers will be asked to recount their experiences of offering screening (healthcare professionals) and the decision-making process regarding consent practices (policy decision-makers). By exploring lived experiences of the consent process we will engage participants in a contextualised discussion before embarking on the more abstract second part of the interview.

In the second portion of the interview, all stakeholders will be encouraged to discuss their attitudes toward consent practices for NBS. Initial discussion will draw on existing debates in the literature regarding the need (or not) for informed consent. Participants will be invited to discuss what this might mean in the context of NBSboth in terms of ethical requirements to achieve consent and practical needs to achieve these requirements-but also to compare this to the alternative approaches such as an implied consent model and mandatory screening. In doing so we will explore the perceived need for parental authorisation, levels of deliberation and identify perceptions regarding the necessary components required for permissible approaches to participation in newborn screening programmes.

In all cases, interviews will be audio-recorded, transcribed verbatim and imported into qualitative data analysis software for analysis. During the process of transcription, data will be anonymised and made available to interviewees for comment.

\section{Data analysis}

The examination of the transcripts will follow a thematic analysis approach ${ }^{61}$ in which textual data is coded and labelled in an inductive manner. This process of coding is iterative, with data analysis using the constant comparison method occurring alongside the interviews. As such, data analysis will continue in parallel to the conduct of interviews, allowing us to modify future interviews should themes emerge that were not part of the original schedule. This approach will allow for the revision, combination or separation of codes in light of new data. ${ }^{62} 63$ As we are taking a comparative approach, comparing stakeholder attitudes and experiences rather than purely describing individual experiences, each newly coded incident will be compared both within and across cases and stakeholder groups to previous incidents in order to refine or revise the code. ${ }^{64}$ After an initial phase of 


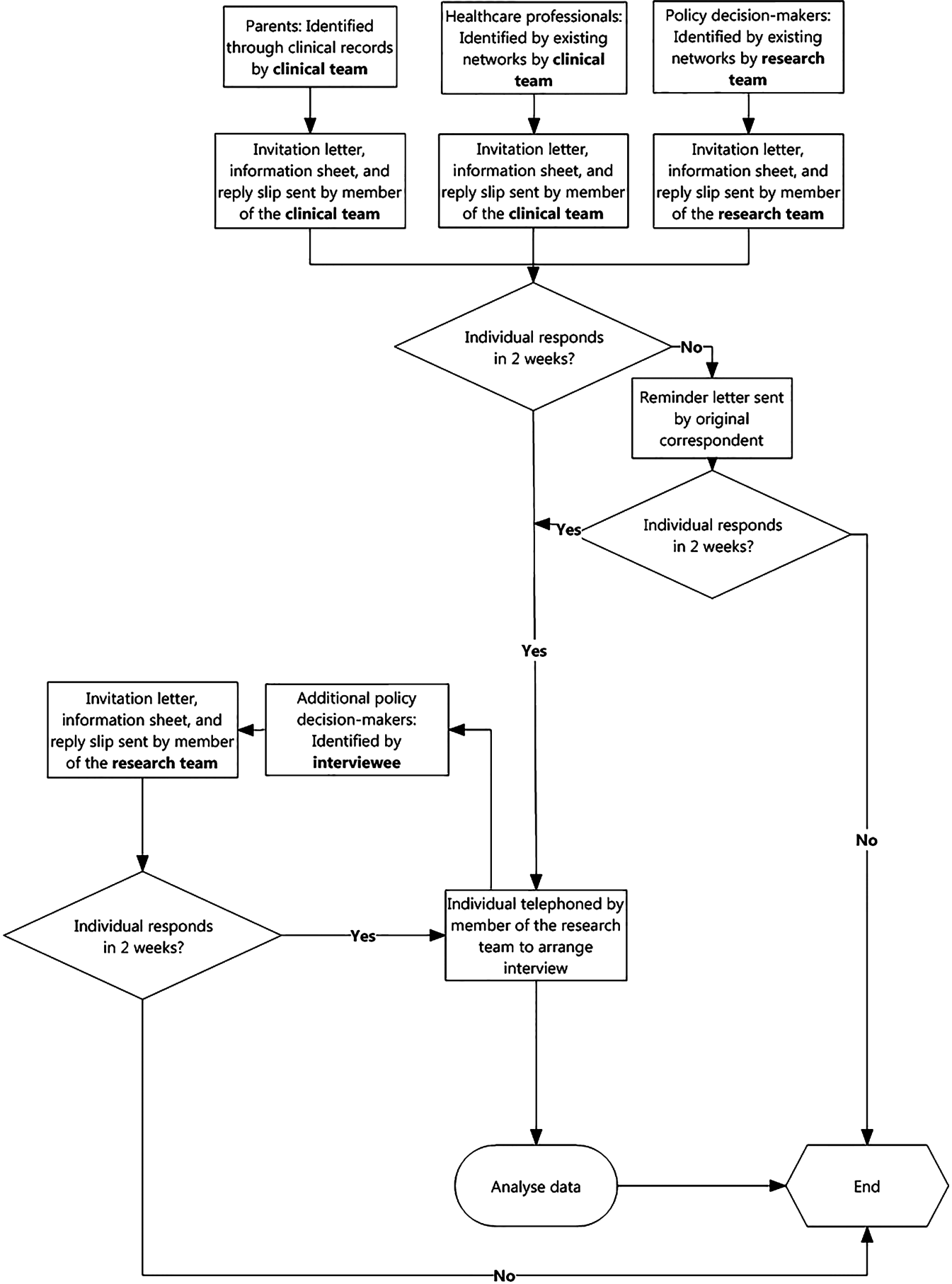

Figure 1 Recruitment process.

open coding, individual codes will be grouped into overarching themes or constructs through a process of data reduction.

Analyses will focus on identifying: how current consent practices to NBS are described and experienced by different stakeholders; individual meanings of terms such as 'informed consent', 'standard of care', and 'implied consent' and; attitudes toward different approaches to NBS and what these approaches imply for practice. By understanding how individuals define consent, we will be able to shed light on implicit assumptions that may in turn provide explanatory insights into differing attitudes toward the applicability of different approaches to consent for NBS. In addition, by inviting respondents to explore definitions of constructs it will be possible to map these to existing definitions and identify areas of difference in meaning.

Interviews will be coded independently by two researchers who will then discuss between themselves, before presenting their analyses to the broader team for comments and further discussion. This process of dual coding has been suggested as a qualitative comparator to traditionally 
quantitative notions of inter-rater reliability. While quantitative approaches have generally been resisted in qualitative approaches in favour of standards of 'credibility', $65-67$ empirical research has indicated the utility of dual coding. ${ }^{67}$ In addition, transcripts will be made available to interviewees for comment. Such feedback, or 'respondent validation', ${ }^{66}$ from participants has been argued for in terms of confirming the validity of the data. ${ }^{47}$ This postinterview interaction may also serve as part of the debriefing for researcher and interviewee and serve as a way to obtain feedback about the research in general. ${ }^{68}$

\section{ETHICS AND DISSEMINATION Ethics}

Potential participants will be sent an invitation letter, information sheet, consent form and return slip. All participants will provide an initial consent to arrange an interview, either in person or in writing. Consent will be reaffirmed from all participants on the date of the interview.

\section{Dissemination}

This study will present the first empirical data comparing stakeholder opinions and experiences of consent practices to newborn screening. Understanding how stakeholders interpret key terminology, such as 'informed consent', will assist lexical decisions when preparing educational materials to ensure consistent messaging and facilitate understanding of newborn screening. Moreover, our results will facilitate better understanding of where conflicts in attitudes regarding the application of consent approaches stem from, and will again inform educational approaches. Our Knowledge Translation strategy directly engages investigators who are closely involved with the development and implementation of newborn screening programmes. Specifically our study team contains the key individuals situated within the provincial screening programmes. In addition, the team includes several members of provincial screening committees that provide advice regarding newborn screening policy. We expect to publish at least three main manuscripts, each focusing on the core aspects of the interviews: how current consent practices to NBS are described and experienced by different stakeholders; individual meanings of terms such as 'informed consent', 'standard of care', and 'implied consent'; and attitudes toward different approaches to newborn bloodspot screening. We will also present our findings at appropriate academic and clinical conferences, nationally and internationally. Throughout the study, we will maintain a web presence via University websites and social media. A summary of results will also be sent to participants who have indicated a wish to receive them. Supplementary funding will also be sought to hold a workshop for key stakeholders, including parent representatives. This will be particularly important in terms of disseminating our findings to other provinces-there is no pan-Canadian organisational structure for NBS programmes in Canada, and as such, we will rely on existing networks of collaboration.

\section{Author affiliations}

${ }^{1}$ Department of Epidemiology and Community Medicine, University of Ottawa, Ottawa, Ontario, Canada

${ }^{2}$ Clinical Epidemiology, Memorial University, St. John's, Newfoundland and Labrador, Canada

${ }^{3}$ Ottawa Hospital Research Institute, Clinical Epidemiology Program, Ottawa, Ontario, Canada

${ }^{4}$ Child Health Evaluative Sciences, The Hospital for Sick Children Research Institute, Toronto, Ontario, Canada

${ }^{5}$ Institute of Health Policy Management and Evaluation, University of Toronto, Toronto, Canada

${ }^{6}$ Newborn Screening Ontario, Children's Hospital of Eastern Ontario (CHEO), Ottawa, Ontario, Canada

${ }^{7}$ Better Outcomes Registry and Network (BORN), Children's Hospital of

Eastern Ontario (CHEO), Ottawa, Ontario, Canada

${ }^{8}$ Faculty of Medicine, Memorial University, St. Johns, Newfoundland and

Labrador, Canada

${ }^{9}$ Eastern Health, St. John's, Newfoundland and Labrador, Canada

Contributors SGN developed the initial study concept, led the writing of the manuscript, ethics application (ON), contributed to data collection and analysis, and coordinated the study. LTe contributed to the preparation of the manuscript, ethics application (ON), and data collection. HE contributed to the study design, writing of the manuscript, ethics application (NL), participant recruitment (NL), and data analysis. JCB contributed to the development of the interviews, provided input regarding empirical assessment of informed consent, and preparation of the manuscript. BKP contributed to the study design, participant recruitment strategies, and preparation of the manuscript. RZH contributed to the study design, participant recruitment approaches, and preparation of the manuscript. PC contributed to the study design, parent and healthcare professional recruitment (ON), and preparation of the manuscript. JMi and JMa contributed to the study design, parent and healthcare professional recruitment (ON), and preparation of the manuscript. DP contributed to the study design, input to the ethics application (ON and NL), provided ethical guidance for interview guides, and preparation of the manuscript. LTu contributed to the study design, participant recruitment, and preparation of the manuscript. BJW was responsible for overall coordination and management of the study, oversaw participant recruitment for policymakers (ON), and contributed to the writing of the manuscript and ethics application (ON).

Funding This work is supported by the Canadian Institutes of Health Research through the Open Operating grant competition (competitive, peer reviewed), reference number EOG-131589.

\section{Competing interests None.}

Ethics approval This study received ethics approval from the Ottawa Health Science Network Research Ethics Board, the Children's Hospital of Eastern Ontario Research Ethics Board (both Ontario), and the Health Research Ethics Authority (Newfoundland and Labrador).

Provenance and peer review Not commissioned; internally peer reviewed.

Open Access This is an Open Access article distributed in accordance with the Creative Commons Attribution Non Commercial (CC BY-NC 4.0) license, which permits others to distribute, remix, adapt, build upon this work noncommercially, and license their derivative works on different terms, provided the original work is properly cited and the use is non-commercial. See: http:// creativecommons.org/licenses/by-nc/4.0/

\section{REFERENCES}

1. Padilla CD, Therrell BL. Newborn screening in the Asia Pacific region. J Inherit Metab Dis 2007;30:490-506.

2. Saadallah AA, Rashed MS. Newborn screening: experiences in the Middle East and North Africa. J Inherit Metab Dis 2007;30:482-9.

3. Bodamer OA, Hoffmann GF, Lindner M. Expanded newborn screening in Europe 2007. J Inherit Metab Dis 2007;30:439-44.

4. Burgard P, Rupp K, Lindner M, et al. Newborn screening programmes in Europe; arguments and efforts regarding harmonization. Part 2. From screening laboratory results to 
treatment, follow-up and quality assurance. J Inherit Metab Dis 2012;35:613-25.

5. Therrell BL, Adams J. Newborn screening in North America. J Inherit Metab Dis 2007;30:447-65.

6. Borrajo GJC. Newborn screening in Latin America at the beginning of the 21st century. J Inherit Metab Dis 2007;30:466-81.

7. Wilson K, Kennedy SJ, Potter B, et al. Developing a national newborn screening strategy for Canada. Health Law Review 2010;18:31-9.

8. Canadian Organization for Rare Disorders. Newborn screening in Canada status report. Toronto, ON: Canadian PKU and Allied Disorders, 2012.

9. Araia $\mathrm{MH}$, Potter BK. Newborn screening education on the internet: a content analysis of North American newborn screening program websites. J Community Genet 2011;2:127-34.

10. Dhondt JL. Implementation of informed consent for a cystic fibrosis newborn screening program in France: low refusal rates for optional testing. J Pediatr 2005;147(3 Suppl):S106-8.

11. Padilla CD, Therrell BL, Jr. Consolidating newborn screening efforts in the Asia Pacific region: networking and shared education. J Community Genet 2012;3:35-45.

12. Huang MC, Lee CK, Lin SJ, et al. Parental consent for newborn screening in southern Taiwan. J Med Ethics 2005;31:621-4.

13. Pollitt RJ. International perspectives on newborn screening. J Inherit Metab Dis 2006;29:390-6.

14. Nicholls SG. Proceduralisation, choice and parental reflections on decisions to accept newborn bloodspot screening. J Med Ethics 2012;38:299-303.

15. Little J, Potter B, Allanson J, et al. Canada: public health genomics. Public Health Genomics 2009;12:112-20.

16. Detmar S, Hosli E, Dijkstra N, et al. Information and informed consent for neonatal screening: opinions and preferences of parents. Birth 2007;34:238-44.

17. Kerruish NJ, Robertson SP. Newborn screening: new developments, new dilemmas. J Med Ethics 2005;31:393-8.

18. Acharya K, Ackerman PD, Ross LF. Pediatricians' attitudes toward expanding newborn screening. Pediatrics 2005;116:e476-84.

19. Campbell E, Ross LF. Parental attitudes regarding newborn screening of PKU and DMD. Am J Med Genet 2003;120A:209-14.

20. Godard B, ten Kate L, Evers-Kiebooms G, et al. Population genetic screening programmes: principles, techniques, practices, and policies. Eur J Hum Genet 2003;11(Suppl 2):S49-87.

21. Hiraki S, Ormond KE, Kim K, et al. Attitudes of genetic counselors towards expanding newborn screening and offering predictive genetic testing to children. Am J Med Genet Part A 2006;140:2312-19.

22. Kemper AR, Wake MA. Duchenne muscular dystrophy: issues in expanding newborn screening. Curr Opin Pediatr 2007;19:700-4.

23. Botkin JR, Clayton EW, Fost NC, et al. Newborn screening technology: proceed with caution. Pediatrics 2006;117:1793-9.

24. Ross LF. Newborn screening for lysosomal storage diseases: an ethical and policy analysis. J Inherit Metab Dis 2012;35:627-34.

25. Etchegary H, Dicks E, Hodgkinson K, et al. Public attitudes about genetic testing in the newborn period. J Obstet Gynecol Neonatal Nurs 2012;41:191-200.

26. Wilcken B. Ethical issues in newborn screening and the impact of new technologies. Eur J Pediatr 2003;162:S62-6.

27. Grob R. Parenting in the genomic age: the 'cursed blessing' of newborn screening. New Genet Soc 2006;25:159-70.

28. Hewlett J, Waisbren SE. A review of the psychosocial effects of false-positive results on parents and current communication practices in newborn screening. J Inherit Metab Dis 2006;29:677-82.

29. Buchbinder M, Timmermans S. Newborn screening and maternal diagnosis: rethinking family benefit. Soc Sci Med 2011;73:1014-18.

30. Buchbinder M, Timmermans S. Newborn screening for metabolic disorders: parental perceptions of the initial communication of results. Clin Pediatr 2012;51:739-44.

31. Ross LF. Mandatory vesrsus voluntary consent for newborn screening? Kennedy Inst Ethics J 2010;20:299-328.

32. Therrell BL, Johnson A, Williams D. Status of newborn screening programs in the United States. Pediatrics 2006;117(5 Pt 2):S212-52.

33. UK Newborn Screening Programme Centre. Guidelines for newborn blood spot sampling. London, UK: UK Newborn Screening Programme Centre, 2008.

34. Araia $\mathrm{MH}$, Wilson $\mathrm{BJ}$, Chakraborty $\mathrm{P}$, et al. Factors associated with knowledge of and satisfaction with newborn screening education: a survey of mothers. Genet Med 2012;14:963-70.

35. Hanley WB. Newborn screening in Canada-Are we out of step? Paediatr Child Health 2005;10:203-07.

36. Miller FA, Hayeems RZ, Carroll JC, et al. Consent for newborn screening: the attitudes of health care providers. Public Health Genomics 2010;13:181-90.
37. Bowling A. Research methods in health. 2nd edn. Maidenhead: Open University Press, 2004.

38. Araia $\mathrm{MH}$, Wilson $\mathrm{BJ}$, Chakraborty $\mathrm{P}$, et al. Educating parents about newborn screening: mothers' expectations and preferences.

39. Miller FA, Paynter M, Hayeems RZ, et al. Understanding sickle cell carrier status identified through newborn screening: a qualitative study. Eur J Hum Genet 2010;18:303-8.

40. Adair A, Hyde-Lay R, Einsiedel E, et al. Technology assessment and resource allocation for predictive genetic testing: a study of the perspectives of Canadian genetic health care providers. BMC Med Ethics 2009;10:6.

41. Bowling A. Research methods in health. Maidenhead: Open University Press, 2004

42. Hayeems RZ, Miller FA, Bombard Y, et al. Expectations and values about expanded newborn screening: a public engagement study. Health Expect 2013. doi:10.1111/hex.12047

43. Kerruish NJ, Webster D, Dickson N. Information and consent for newborn screening: practices and attitudes of service providers. $J$ Med Ethics 2008;34:648-52.

44. Press N, Clayton EW. Genetics and public health: Informed consent beyond the clinical encounter. In: Khoury MJ, Burke W, Thomson EJ, eds. Genetics and public health in the 21st century. New York, NY: Oxford, 2000:505-26.

45. Davis TC, Humiston SG, Arnold CL, et al. Recommendations for effective newborn screening communication: results of focus groups with parents, providers, and experts. Pediatrics 2006;117(5 Pt 2): S326-40.

46. Sandelowski M. Whatever happened to qualitative description? Res Nurs Health 2000;23:334-0.

47. Miles MB, Huberman AM. Qualitative data analysis: an expanded sourcebook. California: Sage, 1994.

48. Patton M. Qualitative research and evaluation methods. 3rd edn. Thousand Oaks: Sage, 2002

49. Lincoln Y, Guba E. Naturalistic inquiry. New York, Sage, 1985.

50. Krueger RA, Casey MA. Focus groups: a practical guide for applied research. 3rd edn. Thousand Oaks: Sage, 2000

51. Senior V, Marteau TM, Peters TJ. Will genetic testing for predisposition for disease result in fatalism? A qualitative study of parents responses to neonatal screening to familial hypercholesterolaemia. Soc Sci Med 1999;48:1857-60.

52. Miller FA, Paynter M, Hayeems R, et al. Understanding sickle cell carrier status identified through newborn screening: a qualitative study. Eur J Hum Genet 2010;18:303-8.

53. McAllister M, Payne K, Macleod R, et al. Patient empowerment in clinical genetics services. J Health Psychol 2008;13: 895-905.

54. McAllister M, Payne K, Macleod R, et al. What process attributes of clinical genetics services could maximise patient benefits? Eur $J$ Hum Genet 2008;16:1467-76.

55. Francis JJ, Johnston M, Robertson C, et al. What is an adequate sample size? Operationalising data saturation for theory-based interview studies. Psychol Health 2010;25:1229-45.

56. Mason J. Qualitative researching. London: Sage, 1996

57. Arksey H, Knight P. Interviewing for social scientists. London: Sage, 1999.

58. Dawson A, Spencer SA. Informing children and parents about research. Arch Dis Child 2005;90:233-5.

59. Beauchamp TL, Faden RR. Meaning and elements of informed consent. In: Encyclopedia of Bioethics. Reich WT, ed. 2nd ed. New York: MacMillan, New York, 1995:1238-41.

60. del Carmen MG, Joffe S. Informed consent for medical treatment and research: a review. Oncologist 2005;10:636-41.

61. Boyatzis RE. Transforming qualitative information. Thousand Oaks: Sage, 1998.

62. Corbin JM, Strauss AL. Basics of qualitative research. 3rd edn. Thousand Oaks: Sage, 2008.

63. Strauss AL. Qualitative analysis for social scientists. Cambridge University Press, 1996.

64. Fielding NG, Lee RL. Computer analysis and qualitative research. London: Sage, 1998.

65. Morse JM, Barrett M, Mayan M, et al. Verification strategies for establishing reliability and validity in qualitative research. Int J Qual Methods 2002;1:13-22.

66. Murphy E, Dingwall R, Greatbatch D, et al. Qualitative research methods in health technology assessment: a review of the literature. Health Technol Assess 1998;2:1-274.

67. Armstrong D, Gosling A, Weinman J, et al. The place of inter-rater reliability in qualitative research: an empirical study. Sociology 1997;31:597-606

68. Sieber JE. Planning ethically responsible research. Newbury Park: Sage, 1992 